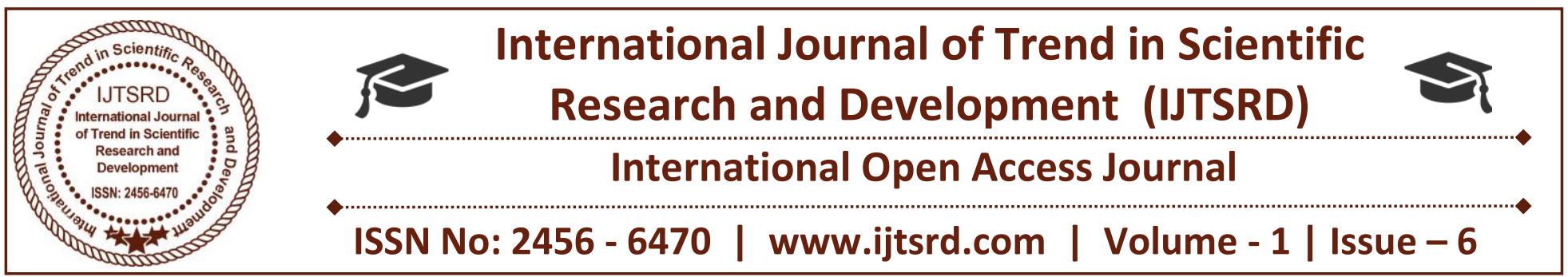

\title{
Studies on Effect of Structural Irregularities on Seismic Performance of Reinforced Concrete Building
}

\author{
S. Boopathi Raja \\ PG Student, Bannari Amman Institute of Technology, \\ Erode District, Tamil Nadu, India
}

\author{
V. Preetha \\ Assistant Professor, Bannari Amman Institute of \\ Technology, Erode District, Tamil Nadu, India
}

\begin{abstract}
An earthquake is a shaking of the surface of the Earth, resulting from the sudden release of energy in the Earth's lithosphere that creates seismic waves. Earthquakes are so far unpreventable and unpredictable, the only option with us is to design and build the structures, which are earthquake resistant. The amount of damage caused by earthquakes could increase in future. This will not be due to a rise in the number and severity of quakes but rather to the increase in world population, linked to the growing number of crowed metropolitan areas and the increase in value of property and material in these areas. In spite of all the weakness in the structure, either code imperfections or error in analysis and design, the structural configuration system has played a vital role in catastrophe. The building configuration has been described as regular and irregular in terms of size and shape of the building, arrangement of structural elements and mass. The study summarizes the different types of structural irregularities i.e. Plan and vertical irregularities in RC building along with their performance during earthquake.
\end{abstract}

Keywords: Earthquake, structural configuration, seismic analysis, irregularities

\section{INTRODUCTION}

Earthquakes are the most unpredictable and devastating natural disasters, which are very difficult to save engineering properties and life. Hence in order to overcome these issues, identifying the seismic performance of the built environment through the development of various analytical procedures, which ensure the structures to withstand during frequent minor earthquakes and produce enough caution whenever subjected to major earthquake events. The behavior of a building during an earthquake depends on several factors such as stiffness, lateral strength, and ductility, simple and regular configurations. The buildings with regular geometry, uniformly distributed mass and stiffness in plan as well as in elevation suffer much less damage compared to irregular configurations. But nowadays thirst and demand of the new generation engineers are planning towards an irregular configuration for better aesthetic perspective. Hence earthquake engineering has developed the key issues in understanding the role of different types of building configurations

When a building is subjected to seismic forces, it is being opposed by horizontal inertia forces which are generated from the building. The resultant of these forces is assumed to act through the center of mass (C.M) of the building. The vertical members in the structure resist these forces and the total resultant of these systems of forces act through a point called as center of stiffness (C.S). When the center of mass and center of stiffness does not coincide, eccentricities are developed in the buildings which further generate torsion. When the buildings are subjected to lateral loads, then phenomenon of torsional coupling occurs due to interaction between lateral loads and resistant forces. Eccentricity may occur due to presence of structural irregularities. Seismic analysis is a division of structural analysis and it involves the calculation of 
the different response of a building structure subjected to earthquakes with different irregularities.

\section{TYPES OF SEISMIC ANALYSIS}
a. Equivalent lateral force
b. Response spectrum analysis
c. Elastic time history analysis
d. Push over analysis
e. Inelastic time history analysis

\section{a. Equivalent lateral force:}

Seismic analysis of most of the structures is still carried out on basis of lateral force assumed to be equivalent to the actual loading. This method is usually conservative for low to medium height buildings with regular conformation.

\section{b. Response spectrum analysis:}

This method is applicable for those structures where modes other than the fundamental one affect significantly the response of the structure. Modal analysis leads to the response history of the structures to a specified ground motion however; the method is usually used in conjunction with a response spectrum.

\section{c. Elastic time history analysis:}

A linear time history analysis overcomes all the disadvantages of modal response spectrum analysis, provided non-linear behavior is not involved. This method requires greater computational efforts for calculating the response at discrete times.

\section{d. Push over analysis:}

The push over analysis of a structure is a static nonlinear analysis under permanent vertical loads and gradually increasing lateral loads. On a building frame, load or displacement is applied incrementally; the formation of plastic hinges, stiffness degradation and plastic rotation are monitored. This type of analysis enables weakness in the structure to be identified.

\section{e. Inelastic time history analysis:}

A seismically deficient building will be subjected to inelastic action during design earthquake motion. The inelastic time history analysis of the building under strong ground motions brings out the region of weakness and ductility demand in structure. This is most rational method available for assessing building performance.

\section{IRREGULARITIES IN A BUILDING}

Irregularities are categorized in two types

I. Vertical irregularities referring to sudden change to strength, stiffness, geometry and mass results in irregular distribution of forces and deformation over the height of building

II. Horizontal irregularities which refer to asymmetrical plan shapes or discontinuities in the horizontal resisting elements such as large openings, re-entrant corners and abrupt changes resulting in torsion, diaphragm deformation

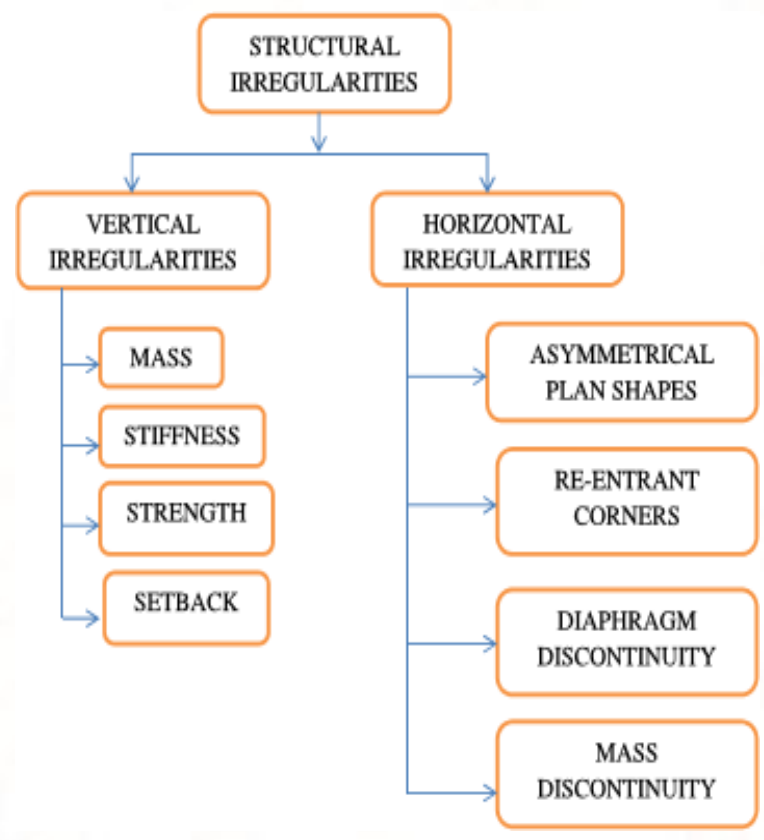

Fig: 1 Classification of Irregularities

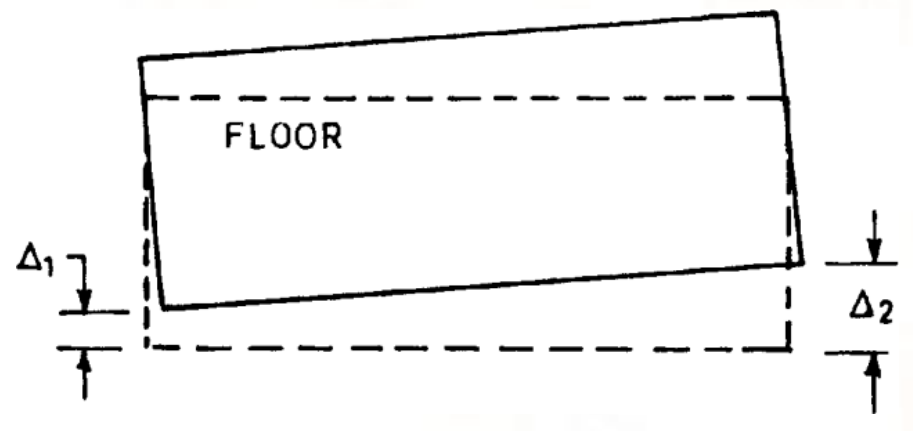

Fig 2: Torsional irregularity 

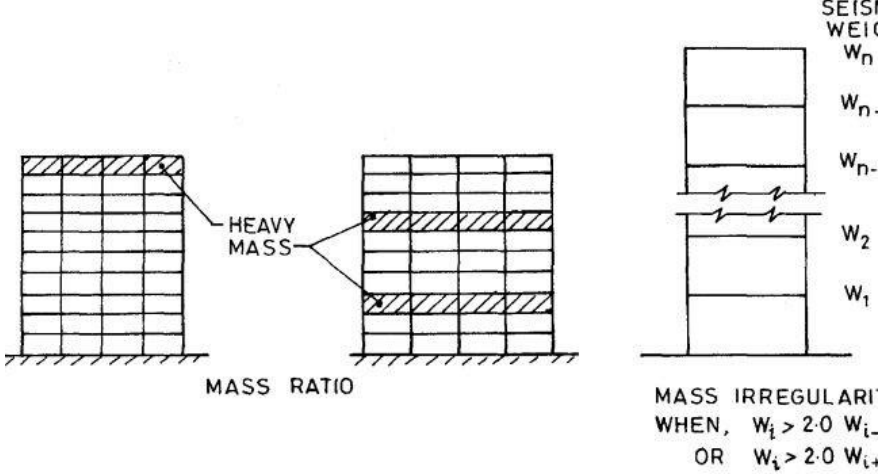

Fig 3: Massirregularity

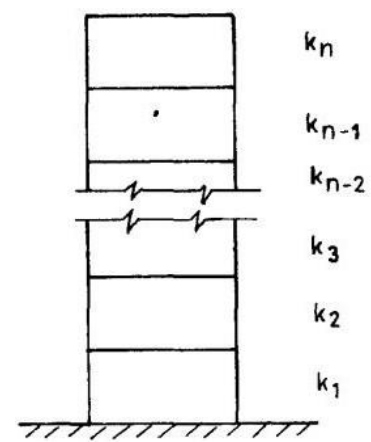

SOFT STOREY WHEN

$k_{i}<0.7 k_{i+1}$ OR $k_{i}<0.8\left(\frac{k_{i+1}+k_{i+2}+k_{i+3}}{3}\right.$

Fig 4: Stiffness irregularity
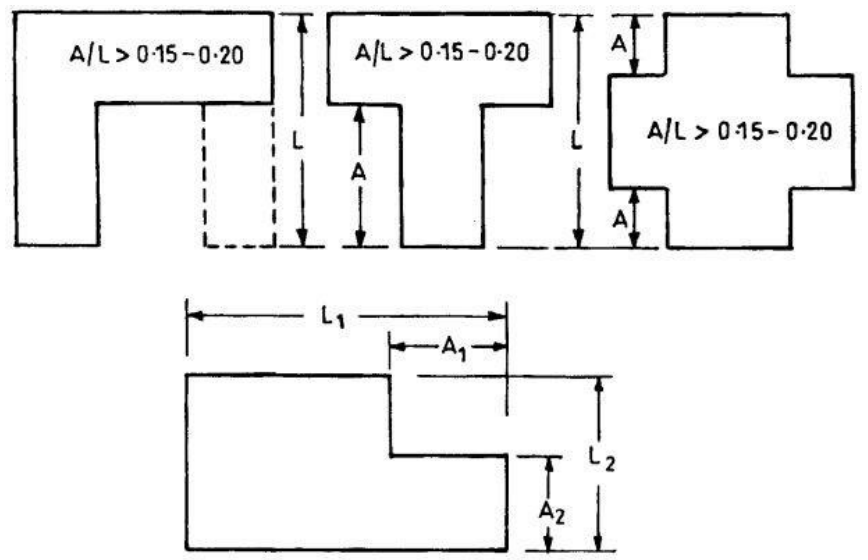

Fig 5: Reentrant corner

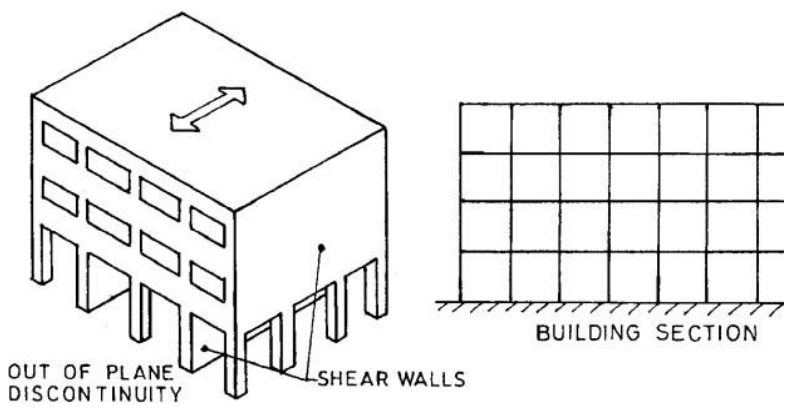

Fig 6: Out plane offset

\section{REVIEW OF LITERATURE}

Mahesh N. Patil, Yogesh N. Sonawane[1] proposed a study on earthquake response of symmetric multistoried building by manual calculation and with the help of ETABS, which includes seismic coefficient method as recommended by IS 1893:2002. The responses obtained by manual analysis as well as by soft computing were compared. Load considered for the analysis is Live load $3 \mathrm{KN} / \mathrm{m} 2$,Zone: III,soil type: II, Response reduction factor: $\mathrm{R}=3$,Importance factor: 1, Damping: 5\%, Time period: $0.427 \mathrm{sec}$. The results observed was gradual increase in the value of lateral forces from bottom floor to top floor in both manual as well as software analysis and the calculation of seismic weight by both manual analysis as well as software analysis gives exactly same result. But slight variation in the values of base shear in manual analysis as well as software analysis whereas base shear values obtained by manual analysis are slightly higher than software analysis.

Yasser Alashker, SohaibNazar et al [2] proposed a study on static pushover analysis, an attempt by the structural engineers to evaluate the real strength of the structure and it promises to be a useful and effective tool for performance-based design. In pushover analysis, building is subjected to incremental lateral loads at different levels representing the inertial forces due to ground shaking during earthquake. The overall plan dimensionsare $20 \mathrm{~m} \times 20 \mathrm{~m}, 25 \mathrm{~m} \times 16 \mathrm{~m}, 28.5$ $\mathrm{m} \times 14 \mathrm{~m}$ and $40 \mathrm{~m} \times 10 \mathrm{~m}$ having same area of 400 $\mathrm{m} 2$. The buildings are five-story with height of 15.2 $\mathrm{m}$. Columns and beams sizes are $500 \times 300 \mathrm{~mm}$ and have been modeled as frame elements while in-plane rigidity of the slab is simulated using rigid diaphragm action. The formation of plastic hinge starts with the yielding of structural members of lower stories and then spread to upper stories with yielding of intermediate columns. Significantly, dimensions of plan influence the seismic behavior of the buildings. Owing to that base shear, significantly increases with increase in plan aspect ratio. The total number of hinges formed at different performance level is increased, by increasing plan aspect ratio, which may lead to building deficiency of resisting seismic loads. 
International Journal of Trend in Scientific Research and Development (IJTSRD) ISSN: 2456-6470

\section{Snehal s. Pawar, sanjaybhadke,}

priyankakamble[3] presented the concept of irregularity. Damage occurred during an earthquake, in a structure generally initiates at location of the structural weakness present in the building systems. These weaknesses trigger further structural deterioration, which leads to the structural collapse, which is due to geometry, mass discontinuity and stiffness of structure. The structures having this discontinuity are known as Irregular structures. It is important to have simpler and regular shapes of frames as well as uniform load distribution around the building because irregularities are harmful for the structures. Therefore, as far as possible irregularities in a building are to be avoided. In case if irregularities have to be included for any reason, they must be designed properly.

Nonika. N, Mrs. GargiDandaDe [4] proposed a study on irregularity by considering a plan of 5 bays $\mathrm{X} 5$ bays, 16 storied structure with provision of lift core walls and each storey height $3.2 \mathrm{~m}$, havingno irregularity in elevation and plan. It is Analyzedusing response spectrum and equivalent static method.Base shear and lateral displacements are gradually increasing with increase in zone. The lateral displacement was found to be less in regular model compare to vertical irregular model. The base shear is almost same in regular model and irregular model, max base shear in zone for regular was $1591.75 \mathrm{KN}$ and $1573.51 \mathrm{KN}$ for irregular. If the stiffness of structures increases, the frequency also increases.

Amit Singh, HimankGhulyani[5] Deals with the seismic response of the multistory building made up of different material like Concrete and Steel to choose best alternative, which has good seismic performance. According to their research, Steel building has $25.39 \%$ less seismic weight when compared to RCC building. In addition to that Steel building has average $26 \%$ lower storey shear than RCC building. Storey displacement is increased by 6 times for RCC and 11 times for steel building, when infill wall is not considered in the analysis.

\section{CONCLUSION:}

From the results of various researchers the following conclusion were arrived as follows.

- The moments and shear forces are always maximum when first storey is soft for all types of buildings.

- When drift is observed in a storey where the stiffness is reduced.

- When stiffness of the structure increases with increase in frequency. Stiffness is dependent on mass of the structure.

o The vertically irregular buildings have performed very poorly during earthquakes. The performance based analysis like pushover analysis is very essential to understand the behavior of the structures. As building becomes more and more vertically irregular (mass irregular), the storey shear goes on increasing as compared to mass regular building.

- If irregularities are to be introduced in a building, they must be designed properly as per the conditions of IS 1893: 2002 (part-1) and IS- 456: 2000 [8], and joints should be made ductile as per IS 13920:1993.

- The complex shaped buildings are more popular, but they carry a risk of sustaining damages during earthquakes. Therefore, such buildings should be designed properly taking care of their dynamic behavior.

\section{REFERENCE}

1) Mahesh N. Patil, Yogesh N. Sonawane, "Seismic Analysis of Multistoried Building" International Journal of Engineering and Innovative Technology (IJEIT) Volume 4, Issue 9, March 2015.

2) Yasser Alashker, SohaibNazar et al, "Effects of Building Configuration on Seismic Performance of RC Buildings by PushoverAnalysis" Open Journal of Civil Engineering, 2015.

3) Snehal s. Pawar1, sanjaybhadke, priyankakamble"Seismic Analysis of Vertically 
Irregular RC Building" International Journal of Current Trends in Engineering \& Research (IJCTER)e-ISSN 2455-1392, Volume 2 Issue 4, April 2016.

4) Nonika. N, Mrs. GargiDandaDe ,"Comparative Studies on Seismic Analysis ofRegular and Vertical Irregular MultistoriedBuilding”, International Journal for Research in Applied Science \& EngineeringTechnology (IJRASET)Volume 3 Issue VII, July 2015.

5) Amit Singh, HimankGhulyani, "Seismic Analysis Of Multi-Storey Rcc Building And Steel Building Using Etabs"International Journal of Advance Engineering and Research Development Volume 4, Issue 7, July -2017. 